Article

\title{
Synergy of National Agricultural Innovation Systems
}

\author{
Dan Wang ${ }^{\circledR}, X^{\prime}$ Du, Jian Sun, Xiangyu Guo * and Yao Chen \\ Northeast Agricultural University, Harbin 150030, China; wd@neau.edu.cn (D.W.); neau711711@163.com (X.D.); \\ sunj_neau@126.com (J.S.); cheny_neau@163.com (Y.C.) \\ * Correspondence: guoxy@neau.edu.cn; Tel.: +86-0451-5519-0558
}

Received: 13 July 2018; Accepted: 17 September 2018; Published: 21 September 2018

check for updates

\begin{abstract}
Synergy among the various components of national agricultural innovation systems (AISs) promotes agricultural development. This paper investigated the innovation synergy among the various innovation elements of national AISs. First, we developed a synergy analysis model consisting of three innovation variables (innovation allocation, innovation output, and innovation potentiality) and one control variable (government policy supports). Secondly, a broad set of innovation indicators was selected to describe the innovation variables and the control variable, and the solutions of the order parameter equation were then calculated to investigate the self-organized synergistic patterns of a panel of the Group of Twenty (G20) countries. The empirical results indicated the following. (1) All of the G20 countries' national AISs had the potential to evolve into more advanced self-organized synergistic states under current government policy support. Furthermore, all of the developing countries were in the active period of synergy, showing stronger synergistic rising powers. However, most of the developed countries were in the stable or general period of synergy, in which synergistic rising powers were relatively weaker; (2) Stronger government policy supports played a positive role in promoting the interaction and collaboration among innovation elements and promoted the national AIS to evolve into a more advanced self-organized synergistic state. This study has important implications for understanding the complex innovation synergy of national AISs, as well as for the design and implementation of agricultural innovation strategies for policy-makers.
\end{abstract}

Keywords: agricultural innovation; innovation system; innovation synergy; the Group of Twenty

\section{Introduction}

Enhancing agricultural innovation has been a permanent preoccupation of public and private organizations since scientific and technological achievements were used to improve agricultural productivity and efficiency in the 16th and 17th centuries [1]. The innovative developments in soil fertilization, mechanization, genetic engineering, cultivation techniques, irrigation techniques, and information technology have been the main drivers behind the increase in agriculture productivity. Nowadays, food security has become more and more affected by the rapidly growing food demand, diminishing natural resources, and climate change. How to feed the growing populations, while simultaneously protecting the environment, remains a complex challenge. Agricultural innovation needs to be a priority to achieve sustainable productivity growth and address the global food challenge [2].

Innovation is a complex phenomenon involving the production, diffusion, and translation of technological knowledge into new products or new processes [3]. The multitudinous links among different innovation stages and the interactions among different actors can lead to knowledge acquisition and mutual knowledge exchange, which strengthens the innovation capability $[4,5]$. The national agricultural innovation is defined as a complex process in which a series of innovative actors create new knowledge, invent new varieties or new technologies, and popularize them 
in agricultural production through collaborative interaction with each other, so as to reach the coordination of economic, social, and ecological benefits in one country [6].

As agricultural innovation becomes increasingly viewed as a far more complex and less linear process, it has become more and more difficult to identify the complex relations that constitute innovation processes. Recently, the agricultural innovation system (AIS) approach [5,7] has become increasingly popular as a tool for analyzing agricultural innovation processes [8-10]. The AIS approach evolved from a transition from the simplistic linear or pipeline model to a complex non-linear or network model of agricultural innovation [11,12]. The AIS approach provides a conceptual framework for the integrated analysis of (1) complex agricultural problems [13]; (2) innovation capacity in the agricultural system to solve these problems [14]; and (3) the structure and function of the AIS, which can enhance or constrain innovation capacities in the agricultural system $[8,9,11]$. Applying the AIS [5,7] framework is particularly promising for sustainable agricultural development, because it can help identify where the most binding constraints on agricultural innovation are located and how better to target interventions to remove such constraints [15].

Innovation performance depends not only on how the individual component part performs in isolation, but also on the quality of the interaction and collaboration among the various elements, that is, the synergies among various elements mark the performance of the innovation system [16]. Therefore, the principal challenge in the agricultural innovation domain using the AIS approach is to understand how the components synergize to produce innovation. However, with a few exceptions [17], there is still a lack in studying AIS synergy. Especially, the analytical approach to the synergy of national AIS is a novel feature.

This paper aims to address this gap by undertaking an innovation synergy analysis of the Group of Twenty (G20) countries' national AISs. The G20 countries with abundant agricultural resources and a large agricultural population account for $80 \%$ of global food. Therefore, the stable development of 'G20 agriculture' has a significant effect on global food security. In recent years, global warming, more frequent and severe natural disasters, constraints on land resources, water resources, and other environmental resources, and the human population growth has caused a tense situation with respect to the supply and demand of agricultural products. 'G20 agriculture' is facing a risk of declining food production capacity and a lack of guarantee regarding food security. In the meeting of G20 agriculture ministers on 3 June 2016 in China, ministers discussed how G20 countries can promote food security, nutrition, sustainable agricultural growth, and rural development worldwide, as well as contribute toward building an innovative, invigorated, interconnected, and inclusive world economy in order to fully achieve the 2030 Agenda for Sustainable Development, including eradicating hunger and extreme poverty. Moreover, the G20 countries have committed to promoting innovation in institutions, policies, science, and technology in order to increase agricultural productivity in a sustainable manner. Understanding the mechanisms that enhance synergy in national AISs helps to increase the success rates in sustainable agricultural productivity.

The key aims of this paper are hence to:

(i) Identify innovation variables based on the existing AIS frameworks and combine these innovation variables in a synergy analysis model;

(ii) Select a broad set of innovation indicators, which will be used to describe the innovation variables and their data sources;

(iii) (Apply the synergy analysis model in the context of G20 countries, with the aim of revealing where particular strengths and weaknesses exist as regards innovation, as well as the level of synergy innovation of the G20 countries' national AISs, and the underlying reasons for these;

(iv) Inform the national AIS policies for sustainable agricultural development.

Addressing this knowledge gap will have important implications for understanding the complex innovation synergy of national AISs, as well as for the design and implementation of agricultural innovation strategies for policy-makers. 


\section{Theoretical Background}

\subsection{Self-Organization Characteristics of National AIS}

"Self-organization is the spontaneous and often seemingly purposeful formation of spatial, temporal, and spatiotemporal structures or functions in systems composed of few or many components" (Haken, 2008) [18]. Self-organization means an enormous reduction of degrees of freedom (entropy) and an increase of 'order'. National AISs show typical self-organization characteristics [17] (as shown in Figure 1):

\section{(1) Nonlinearity}

National agricultural innovation includes a complex set of interactive relationships among multiple innovation actors (including government, private and public agricultural firms, universities and research institutions, intermediary service organizations, and farmers). These innovation actors produce, popularize, and apply various types of technological knowledge. The innovation processes follow a non-linear path, and are characterized by complicated feedback mechanisms [19].

\section{(2) Openness}

National AISs, in the large-scale economic and social systems, have the properties of dissipative structures that widely exchange material, energy, and information with the external environment. There are extensive links with the external environment in every stage of research, development, and the extension of agricultural science and technology. 'Negative entropy' flows, which are generated by exchange with the external environment, reduce the entropy of the national AIS and make the national AIS form an ordered structure.

\section{(3) Fluctuations and non-equilibrium}

In order to achieve sustainable agriculture, the national AISs keep overcoming their own shortcomings and narrowing the gap between themselves and other advanced countries. The positive innovation motivation may provoke various changes (fluctuations) in certain innovation elements of national AISs. A small fluctuation may be enhanced through the interaction of a feedback regulation mechanism, which could cause the resonance of all of the system elements in responding to the change. Under these circumstances, the national AIS will be far from equilibrium, and evolve from the original state to the advanced state.



Figure 1. The self-organized synergistic evolution process of national agricultural innovation systems (AISs). 


\subsection{Synergetics and Belousov-Zhabotinsky (B-Z) Reaction}

Synergetics is an interdisciplinary science that was founded by Hermann Haken in the 1970s and explains the formation and self-organization of patterns and structures in open systems far from thermodynamic equilibrium [20]. The order parameter concept is essential to synergetics, and is generalized by the enslaving principle. Following the enslaving principle, the emerging order parameters reduce the degrees of freedom in the behavior of the single parts of a system, and the dynamics of fast relaxing modes are completely determined by the 'slow' dynamics of only a few order parameters. Synergetics explains the self-organization of patterns in many different systems, such as that of physics, chemistry, biology, and so on [20].

The Belousov-Zhabotinsky (B-Z) reaction [21-23], which was discovered in the 1950s by B. Belousov, is used extensively as a chemical system model in studies on synergetic phenomena [24,25]. Inspired by the $\mathrm{B}-\mathrm{Z}$ reaction, this paper established a metaphorical model of the $\mathrm{B}-\mathrm{Z}$ reaction model to study the innovation synergy of national AISs with self-organization characteristics.

\subsection{Conceptual Frameworks of National AISs}

To conduct a synergy analysis from the innovation system perspective, the analytical framework of this paper was primarily based on the AIS approach of Wang (2018) and Spielman (2008). The two approaches developed conceptual frameworks that captured the essential elements of national AIS, the linkages among their components, and the environment that enables innovation. The two frameworks combined conventional input and output indicators with more process-oriented, systems-specific indicators $[6,9]$.

This clear division into structural elements provided a practical approach for the synergy analysis model based on the B-Z reaction. The collaborative relationships among the sub-units of national AISs were analyzed in the context of the present innovation allocation, innovation output, and the potential innovation capabilities, which were the metaphors of the three major chemical substances $\left(\mathrm{Br}-, \mathrm{HBrO}_{2}\right.$, and $\mathrm{Ce}(\mathrm{IV})$ ) of the B-Z reaction model.

\section{Methodology}

\subsection{Selection of State Variables and Determination of Order Parameters}

Three innovation variables (innovation allocation variable, innovation output variable, and innovation potentiality variable) were proposed as state variables of synergy in national AISs.

The innovation allocation state variable was composed of agricultural innovation foundation and bridging factors. The innovation foundation represented the input and contribution of one country to agricultural innovation development. A favorable innovation foundation can provide effective supports for innovation activities. Meanwhile, it is important to recognize that innovation often relies on a diversity of bridging components facilitating the transfer of knowledge and information among these diverse domains. Innovation outputs were the achievements and value realization of agricultural innovation activities. The innovation output state variable was used to represent the quantity and quality of innovation outcomes. Innovation is a recurring process: these new inputs and outputs go back to the innovation environment circularly and optimize self-allocation to achieve a higher-level innovation stage. This process was described by the innovation potentiality state variable.

The order parameter can be interpreted as the amplitude of the unstable modes determining the macroscopic pattern. From the dynamic perspective, the innovation potentiality state variable embodied the quality of interaction and collaboration among all of the innovation resources and determined the future state of the system [24]. The innovation potentiality state variable, as the main driving force in the evolution of national AISs, had similar features to the order parameter. Therefore, the innovation potentiality state variable was proposed as the order parameter of the synergistic evolution of national AISs. 


\subsection{Synergy Analysis Model Based on the B-Z Reaction}

Logistical equations have been widely used for simulating the B-Z reaction model to investigate synergy evolution [24-26]. This paper used a set of logistic regression equations, which were revised from Zhang's model [25], to represent the synergy evolution process of national AISs. The equations consisted of three state variables $\left(y_{1}, y_{2}\right.$, and $\left.y_{3}\right)$, three adjustment parameters $(\alpha, \beta$, and $\gamma)$, and one control variable $\theta$, which were the metaphors of three major chemical substances $(X, Y$, and $Z)$, chemical reaction rates, and control parameters of the B-Z reaction model, respectively. Detailed descriptions of different types of variables and parameters are presented in Table 1.

Table 1. Variables and parameters of national AISs.

\begin{tabular}{ll}
\hline \multicolumn{1}{c}{ Variables and Parameters } & \multicolumn{1}{c}{ Description } \\
\hline Innovation potentiality state variable $y_{1}$ & Representing the development speed of national AISs. \\
\hline Innovation allocation state variable $y_{2}$ & $\begin{array}{l}\text { Representing the foundation and bridging level of } \\
\text { national AISs. }\end{array}$ \\
\hline Innovation output state variable $y_{3}$ & Representing the output level of national AISs. \\
\hline Control variable of government policy $\theta$ & $\begin{array}{l}\text { Representing the comprehensive index of government } \\
\text { policy supports for the synergy of national AISs. }\end{array}$ \\
\hline Innovation potentiality adjustment parameter $\alpha$ & $\begin{array}{l}\text { Measuring the development capabilities of national AISs, } \\
\text { obtained through indicators. }\end{array}$ \\
\hline Innovation allocation adjustment parameter $\beta$ & $\begin{array}{l}\text { Measuring the foundation and bridging capabilities of } \\
\text { national AISs, obtained through indicators. }\end{array}$ \\
\hline Innovation output adjustment parameter $\gamma$ & $\begin{array}{l}\text { Measuring the output capabilities of national AISs, } \\
\text { obtained through indicators. }\end{array}$ \\
\hline
\end{tabular}

The calculation models of the innovation adjustment parameters (Equation (1)) and control variable of government policy (Equation (2)) were defined as follows:

$$
\left\{\begin{aligned}
\alpha & =\sqrt[i]{\prod_{i=1}^{n} \frac{\alpha_{i}}{\bar{\alpha}_{i}}}(i=1,2,3 \ldots n) \\
\beta & =\sqrt[i]{\prod_{i=1}^{n} \frac{\beta_{i}}{\beta_{i}}}(i=1,2,3 \ldots n) \\
\gamma & =\sqrt[i]{\prod_{i=1}^{n} \frac{\gamma_{i}}{\gamma_{i}}}(i=1,2,3 \ldots n)
\end{aligned}\right.
$$

where $\alpha_{i}, \beta_{i}$, and $\gamma_{i}$ are the $i$ th indicator values of the innovation potentiality state variable, the innovation allocation state variable, and the innovation output state variable, respectively. $\overline{\alpha_{i}}, \overline{\beta_{i}}$, and $\overline{\gamma_{i}}$ are the average values.

$$
\theta=\sqrt[i]{\prod_{i=1}^{n} \frac{\theta_{i}}{\bar{\theta}_{i}}}(i=1,2,3 \ldots n)
$$

where $\theta_{i}$ is the $i$ th indicator value of the government policy supports, and $\overline{\theta_{i}}$ is the average value of all countries in the $i$ th indicator.

The synergy analysis equations were built as follows. First, the innovation potentiality domain was represented by Equation (3). The innovation potentiality state variable $y_{1}$ is influenced by itself and the innovation allocation state variable $y_{2}$ in the time dimension $(t)$.

$$
\frac{1}{\alpha} \frac{d y_{1}}{d t}=\theta y_{1}+\theta \frac{\beta}{\alpha} y_{2}-\beta y_{1} y_{2}+\eta_{1} y_{2}^{l}
$$

where $\frac{d y_{1}}{d t}$ is a derivative of $y_{1}$ with respect to time, interpreted as the rate of change of $y_{1} . \theta y_{1}$ and $\theta \frac{\beta}{\alpha} y_{2}$ are the self-influencing factor and the influencing factor of $y_{2}$ on $y_{1}$, respectively. Under the influence of control variable $\theta, \theta \frac{\beta}{\alpha}$ is the influencing coefficient. $-\beta y_{1} y_{2}+\eta_{1} y_{2} l$ is the influencing factor of $y_{2}$ on 
$y_{1}$ without the influence of $\theta, \eta_{1} y_{2}{ }^{l}$ represents the synergy of the innovation allocation optimization, and $\eta_{1}$ and $l$ are synergistic coefficients.

Secondly, Equation (4) describes the impact of $y_{2}$ itself, the innovation potentiality state variable $y_{1}$, and the innovation output state variable $y_{3}$ on $y_{2}$.

$$
\frac{1}{\beta} \frac{d y_{2}}{d t}=-\theta y_{2}-\alpha y_{1} y_{2}+\frac{\gamma}{\beta} y_{3}
$$

where $\frac{d y_{2}}{d t}$ represents the change rate of $y_{2}$, and $-\theta y_{2}$ is the self-influencing factor under the influence of control variable $\theta$. The negative influencing coefficient indicates that the increase of innovation resources will destroy the original allocation structure and have a negative impact on the current innovation allocation. $-\alpha y_{1} y_{2}$ is the influencing factor of $y_{1}$ on $y_{2}$; the accelerating development of national AISs will consume more resources, which results in the reduction of the resource flow and resource sharing among the innovation actors, and furthermore weakens the innovation allocation capability of national AISs. $\frac{\gamma}{\beta} y_{3}$ represents the influencing factor of $y_{3}$ on $y_{2}$, and the innovation output shows the effectiveness of the innovation allocation.

Third, the transform process from innovation input to innovation output may be delayed because of the interaction and influence of various factors in national AISs. Therefore, the innovation input cannot generate innovation output and profits immediately [27]. The innovation output state variable $y_{3}$ is influenced by itself and the innovation potentiality state variable $y_{1}$ in the time dimension, as shown in Equation (5):

$$
\frac{1}{\gamma} \frac{d y_{3}}{d t}=-\eta_{2} y_{3}+\eta_{3} \theta \frac{\alpha}{\gamma} y_{1}
$$

where $\frac{d y_{2}}{d t}$ represents the change rate of $y_{3}$, and $-\eta_{2} y_{3}$ is the self-influencing factor without the influence of control variable $\theta$. With self-consumption, the output of the national AIS will be gradually reduced. $\eta_{3} \theta \frac{\alpha}{\gamma} y_{1}$ indicates that the innovation outputs can be greatly improved with the acceleration of development of national AISs, and $\eta_{3}$ is the potentiality coefficient of a national AIS to develop into a more ordered state.

In this paper, $\eta_{1}=2$ and $l=2$ depicts that the synergistic innovation allocation domain can accelerate the promotion of the agricultural innovation capability. $\eta_{2}=1$ indicates that the national AIS can maintain the current situation without external influence. $\eta_{3}=2$ indicates that the national AIS has a strong potential to develop into a more ordered state [25]. The synergy analysis model was shown in Equation set (6):

$$
\left\{\begin{array}{l}
\frac{d y_{1}}{d t}=\alpha \theta y_{1}+\beta \theta y_{2}-\alpha \beta y_{1} y_{2}+2 \alpha y_{2}{ }^{2} \\
\frac{d y_{2}}{d t}=-\beta \theta y_{2}-\alpha \beta y_{1} y_{2}+\gamma y_{3} \\
\frac{d y_{3}}{d t}=-\gamma y_{3}+2 \alpha \theta y_{1}
\end{array}\right.
$$

\subsection{Application of Adiabatic Elimination Principle}

The complex phenomena brought about by the collaboration among many subsystems can be described by a few simple concepts. One of the main concepts is the order parameter; another is the adiabatic elimination of the subsystem variables, which is based upon a hierarchy of time constants that is present in most systems [20]. Close to the threshold, the dynamics of the system is then governed by, in general, a few order parameters. That is, the system's equations are satisfied by the order parameters of the system. The adiabatic elimination principle allows for the elimination of the fast state variables and then derives model equations by only including the slow state variables (the order parameters). 
In this paper, the innovation potentiality state variable was set as the order parameter, and the logistical equation of the order parameter was established by means of the adiabatic elimination principle. Here, $\frac{d y_{2}}{d t}=0$ and $\frac{d y_{3}}{d t}=0$, then the following results were obtained:

$$
\left\{\begin{array}{c}
y_{2}=\frac{2 \alpha \theta}{\beta} \frac{y_{1}}{2 y_{1}+\theta} \\
y_{3}=\frac{2 \alpha \theta}{\gamma} y_{1}
\end{array}\right.
$$

The order parameter equation, as shown in Equation (8), was derived from Equations (6) and (7).

$$
\frac{d y_{1}}{d t}=\alpha \theta y_{1}+2 \alpha \theta^{2} \frac{y_{1}}{\alpha y_{1}+\theta}-2 \alpha^{2} \theta \frac{y_{1}^{2}}{\alpha y_{1}+\theta}+\frac{8 \alpha^{3} \theta^{2}}{\beta^{2}} \frac{y_{1}^{2}}{\left(\alpha y_{1}+\theta\right)^{2}}
$$

\section{Selection of Indicators and Data Sources}

Our empirical analysis made use of the analytical framework presented above, investigating the synergy of national AISs for the G20 countries, including Argentina, Australia, Brazil, Canada, China, France, Germany, India, Indonesia, Italy, Japan, Republic of Korea, Mexico, Russian Federation, Saudi Arabia, South Africa, Turkey, the United Kingdom, and the United States (note: The European Union $(\mathrm{EU})$ is a political and economic union, and its major member states are already within the G20, so the EU was not included in this empirical analysis).

Using the analytical framework presented above, this section discussed a broad set of innovation indicators, which are used to describe the three state variables (innovation allocation variable, output variable, and potentiality variable) and the control variable, and identified their data sources. The detailed indicators and their data sources are presented in Tables $2-5$. 
Table 2. Index system of innovation allocation of national AISs. R\&D: research and development.

\begin{tabular}{|c|c|c|c|c|}
\hline Index & Sub-Index & Indicator & Indicator Description and Units of Measure & Sources of Data \\
\hline \multirow{9}{*}{ Allocation of national AISs } & \multirow{3}{*}{ Infrastructure } & Agricultural machinery & Tractors per 100 square kilometers of arable land, total number & $\mathrm{WB}^{\mathrm{a}}$ \\
\hline & & $\begin{array}{l}\text { Information and } \\
\text { communication technology }\end{array}$ & $\begin{array}{l}\text { Average value of individuals using the internet, fixed-telephone } \\
\text { subscriptions, and mobile-cellular telephone subscriptions per } 100 \\
\text { inhabitants, headcounts }\end{array}$ & $\mathrm{ITU}^{\mathrm{b}}$ \\
\hline & & Transportation infrastructure & $\begin{array}{l}\text { Average value of roads, railroad, port, and air transport, index (1-7 scores) } \\
{[1=\text { extremely underdeveloped; } 7=\text { extensive and efficient }]}\end{array}$ & WEF-GCR ${ }^{c}$ \\
\hline & \multirow[b]{2}{*}{ Research foundation } & Ranking by agricultural sciences & $\begin{array}{l}\text { Institutions ranking the world's top } 30 \text { in agricultural sciences, total } \\
\text { number }\end{array}$ & RCCSE $^{\mathrm{d}}$ \\
\hline & & $\begin{array}{l}\text { R\&D level of agricultural } \\
\text { enterprises }\end{array}$ & World-famous agricultural enterprises, total number & RIIET $^{\mathrm{e}}$ \\
\hline & \multirow{2}{*}{ Human capital } & Agricultural researchers & $\begin{array}{l}\text { Number of agricultural researchers (per million rural residents), } \\
\text { headcounts }\end{array}$ & UNESCO-UIS $^{\mathrm{f}}$, FAO ${ }^{\mathrm{g}}$ \\
\hline & & Peasant cultural quality & School life expectancy (primary to tertiary), both sexes (years) & UNESCO-UIS $^{\mathrm{f}}$ \\
\hline & \multirow[b]{2}{*}{ Collaboration foundation } & $\begin{array}{l}\text { University-industry } \\
\text { collaboration }\end{array}$ & $\begin{array}{l}\text { To what extent do business and universities collaborate on R\&D? Index } \\
(1-7 \text { scores) }[1=\text { do not collaborate at all; } 7 \text { = collaborate extensively }]\end{array}$ & WEF-GCR ${ }^{c}$ \\
\hline & & State of cluster development & $\begin{array}{l}\text { How widespread are well-developed and deep clusters, index ( } 1-7 \text { scores) } \\
{[1=\text { nonexistent; } 7=\text { widespread }]}\end{array}$ & WEF-GCR ${ }^{c}$ \\
\hline
\end{tabular}

Notes: ${ }^{a}$ WB: World Bank. ${ }^{b}$ ITU: International Telecommunications Union. ${ }^{c}$ WEF-GCR: World Economic Forum-Global Competitiveness Report. ${ }^{d}$ RCCSE: Research Center for Chinese Science Evaluation. ${ }^{e}$ RIIET: Research Institute of International Economic and Trade (Beijing). ${ }^{\mathrm{f}}$ UNESCO-UIS: United Nations Educational, Scientific, and Cultural Organization-Institute for Statistics. ${ }^{g}$ FAO: Food and Agriculture Organization.

Table 3. Index system of innovation output of national AIS.

\begin{tabular}{|c|c|c|c|c|}
\hline Index & Sub-Index & Indicator & Indicator Description and Units of Measure & Sources of Data \\
\hline \multirow{7}{*}{ Output of national AISs } & \multirow{3}{*}{$\begin{array}{l}\text { Scientific and technological } \\
\text { outcome }\end{array}$} & Agricultural journal papers & Number of agricultural journal papers (per million rural residents), number & Web of Science \\
\hline & & Agricultural patent & Number of agricultural patent (per million rural residents), number & $\mathrm{WIPO}^{\mathrm{h}}$ \\
\hline & & Plant varieties & Number of plant varieties (per million rural residents), number & $\mathrm{WIPO}^{\mathrm{h}}$ \\
\hline & \multirow{3}{*}{ Productivity level } & Index of agricultural production & $\begin{array}{l}\text { Average value of crop production index, food production index, and } \\
\text { livestock production index, index }\end{array}$ & $\mathrm{WB}^{\mathrm{a}}$ \\
\hline & & Agricultural land productivity & Grain yield per unit area, $\mathrm{kg} / \mathrm{ha}$ & $\mathrm{WB}^{\mathrm{a}}$ \\
\hline & & Agricultural labor productivity & Agriculture value added per worker, US\$ & $\mathrm{WB}^{\mathrm{a}}$ \\
\hline & Economic performance & Agricultural value added & Agricultural value added, US\$ & $\mathrm{WB}^{\mathrm{a}}$ \\
\hline
\end{tabular}

Notes: ${ }^{\mathrm{a}}$ WB: World Bank. ${ }^{\mathrm{h}}$ WIPO: World Intellectual Property Organization. 
Table 4. Index system of innovation potentiality of national AISs.

\begin{tabular}{|c|c|c|c|}
\hline Index & Sub-Index & Indicator & Units of Measure \\
\hline \multirow{16}{*}{ Potentiality of national AISs } & \multirow{3}{*}{ Infrastructure potentiality } & Growth rate of agricultural machinery & $\%$ \\
\hline & & Growth rate of information and communication technology & $\%$ \\
\hline & & Growth rate of transportation infrastructure & $\%$ \\
\hline & \multirow{2}{*}{ Research foundation potentiality } & Growth rate of ranking by agricultural sciences & $\%$ \\
\hline & & Growth rate of R\&D level of agricultural enterprises & $\%$ \\
\hline & \multirow{2}{*}{ Human capital potentiality } & Growth rate of agricultural researchers & $\%$ \\
\hline & & Growth rate of peasant cultural quality & $\%$ \\
\hline & \multirow{2}{*}{ Collaboration foundation potentiality } & Growth rate of university-industry collaboration & $\%$ \\
\hline & & Growth rate of cluster development state & $\%$ \\
\hline & \multirow{3}{*}{ Scientific and technological outcome potentiality } & Growth rate of agricultural journal papers & $\%$ \\
\hline & & Growth rate of agricultural patent & $\%$ \\
\hline & & Growth rate of plant varieties & $\%$ \\
\hline & \multirow{3}{*}{ Productivity level potentiality } & Growth rate of index of agricultural production & $\%$ \\
\hline & & Growth rate of agricultural land productivity & $\%$ \\
\hline & & Growth rate of agricultural labor productivity & $\%$ \\
\hline & Economic performance potentiality & Growth rate of added agricultural value & $\%$ \\
\hline
\end{tabular}

Table 5. Index system of the control variable of national AISs. ASTI: agricultural science, technology, and innovation.

\begin{tabular}{ccc}
\hline Index & \multicolumn{1}{c}{ Indicator } & \multicolumn{1}{c}{ Indicator Description and Units of Measure } \\
\hline & Political stability & Political stability and absence of violence/terrorism, index \\
Agricultural knowledge and innovation system support, $\%$
\end{tabular}

Notes: ${ }^{\mathrm{a}}$ WB: World Bank. ${ }^{\mathrm{c}}$ WEF-GCR: World Economic Forum-Global Competitiveness Report. ${ }^{\mathrm{i}}$ OECD: Organization for Economic Co-operation and Development. 


\subsection{Innovation Allocation Indicators}

The main indicators that have been used to describe the innovation allocation domain of national AISs included various foundation and bridging aspects in national agricultural innovation. Four sub-indexes were captured: (1) infrastructure; (2) research foundation; (3) human capital; and (4) collaboration foundation. The first sub-index included agricultural machinery, information and communication technology (ICT), and transportation infrastructure. They were proxies for enabling the infrastructure needed to support innovation in the agricultural sector. The second sub-index captured the country's level of agricultural research and development (R\&D) activities by using (1) ranking by agricultural discipline and (2) $R \& D$ level of agricultural enterprises. The third sub-index captured human capital investment in agricultural innovation. Innovation in many countries is constrained by a lack of human capital, particularly in the fields of research and education. Thus, the number of agricultural researchers was introduced as a proxy for losses of human capital stock in the agricultural R\&D fields. The rural education level is an important determinant of agricultural innovation capability. Hence, peasant cultural quality was included as an indicator within this domain. The fourth sub-index captured the importance of linkages in national agricultural innovation. This was proxied by two indicators: (1) university-industry collaboration, which measured the extent to which businesses collaborated with universities; and (2) the state of cluster development, which measured how widespread well-developed and deep clusters were, based on expert opinion polls conducted by the World Economic Forum (WEF). Many system-oriented indicators were included as the measures of the degree of integration or connectedness of the AISs. For example, the ICT and transportation network available to AIS institutions, as well as the collaboration indicators, might measure the extent of research collaborations among key system actors, primarily public research organizations, public universities, and private companies.

\subsection{Innovation Output Indicators}

Indicators that described the nature and performance of the innovation output domain of national AIS could be divided into three general categories: (1) scientific and technological outcome; (2) productivity level; and (3) economic performance. The scientific and technological outcome captured the extent to which a country's agricultural research and education system actually produced some type of scientific and technological output. The commonly accepted measures of this were the agricultural journal publications [28], the number of patents [27], and plant varieties generated by research organizations and universities. The productivity level captured the extent to which scientific and technological changes in agriculture could help foster productivity growth. These indicators were the index of agricultural production, agricultural land productivity, and agricultural labor productivity. The added agricultural value indicator was identified to capture the relationship between the national AIS and its possible economic performance.

\subsection{Innovation Potentiality Indicators}

Indicators for the innovation potentiality domain were made up of the growth rate, during a certain period, of all of the indicators from the innovation allocation domain and output domain.

Finally, it should be noted that these indicators combined a range of measures, including inputs (tools and information used in innovation processes), outputs (knowledge, goods, and performance resulting from innovation processes), and potentiality (growth rate of all of the above indicators), all of which were potentially useful for the characterization of AISs.

\subsection{Control Variable Indicators}

The control variable of government policy represented the comprehensive index of government policy supports for the synergy of national AISs. The control variable was described by means of the following indicators: (1) political stability, describing the political environment; (2) support for 
agricultural science, technology, and innovation (ASTI), representing the agricultural policy supports for the national AIS; (3) intellectual property protection, measuring the level of intellectual property protection; and (4) policy rationality, indicating whether agricultural policy can balance well the interests of taxpayers, consumers, and producers.

The data of indicators of the innovation allocation domain, innovation output domain, and control variable of government policy were from 2015. Moreover, the data of indicators of the innovation potentiality domain were made up of the growth rate, during a 10-year period (2005-2015), of all of the indicators from the innovation allocation domain and output domain.

\section{Empirical Results}

\subsection{Results of Parameters and the Control Variable}

The values of the three adjustment parameters $(\alpha, \beta$, and $\gamma)$ and control variable $\theta$ were calculated based on the calculation model [see Equations (1) and (2)]. As shown in Table 6, in 2015, the countries whose innovation potentiality $\alpha$ ranked in $1 \sim 10$ were China (0.8266), Turkey (0.2682), Brazil $(0.2479)$, Saudi Arabia (0.0887), Mexico (0.0833), Indonesia (0.0789), Argentina (0.0650), India (0.0635), Italy (0.0554), and the Russian Federation (0.0516). The countries whose innovation allocation $\beta$ ranked in $1 \sim 10$ were the United States (1.5388), France (1.2223), Germany (1.2029), Japan (0.5793), Italy (0.3761), the United Kingdom (0.3565), Australia (0.3308), Canada (0.3166), China (0.2380), and Brazil (0.2215). The countries whose innovation output $\gamma$ ranked in 1 10 were Japan (1.5783), Australia (1.4291), the United States (1.2383), the Republic of Korea (1.0960), Canada (1.0305), France (0.9001), Argentina (0.6604), Germany (0.6325), the United Kingdom (0.5659), and Brazil (0.5543).

Table 6. Results of the adjustment parameters and control variable.

\begin{tabular}{ccccc}
\hline & \multirow{2}{*}{ Item } & \multicolumn{4}{c}{$\mathbf{2 0 1 5}$} \\
\cline { 3 - 5 } Countries & $\boldsymbol{\alpha}$ & $\boldsymbol{\beta}$ & $\gamma$ & $\boldsymbol{\theta}$ \\
\hline & & & & \\
Argentina & 0.0650 & 0.0920 & 0.6604 & 0.3514 \\
Australia & 0.0067 & 0.3308 & 1.4291 & 1.9692 \\
Brazil & 0.2479 & 0.2215 & 0.5543 & 0.7306 \\
Canada & 0.0065 & 0.3166 & 1.0305 & 1.5734 \\
China & 0.8266 & 0.2380 & 0.3284 & 0.7157 \\
France & 0.0204 & 1.2223 & 0.9001 & 1.1365 \\
Germany & 0.0365 & 1.2029 & 0.6325 & 1.2516 \\
India & 0.0635 & 0.0505 & 0.0411 & 0.2887 \\
Indonesia & 0.0789 & 0.0378 & 0.0645 & 0.4572 \\
Italy & 0.0554 & 0.3761 & 0.2594 & 1.0358 \\
Japan & 0.0096 & 0.5793 & 1.5783 & 0.9078 \\
The Republic of Korea & 0.0447 & 0.1501 & 1.0960 & 0.8505 \\
Mexico & 0.0833 & 0.1824 & 0.2498 & 0.7038 \\
The Russian Federation & 0.0516 & 0.0767 & 0.3011 & 0.4555 \\
Saudi Arabia & 0.0887 & 0.0469 & 0.3174 & 0.3596 \\
South Africa & 0.0341 & 0.0666 & 0.2612 & 1.1839 \\
Turkey & 0.2682 & 0.0985 & 0.2824 & 0.1710 \\
The United Kingdom & 0.0054 & 0.3565 & 0.5659 & 1.2345 \\
The United States & 0.0178 & 1.5388 & 1.2383 & 1.0532 \\
\hline
\end{tabular}

There were obvious differences in the values of current control variables. The values were divided into three categories: The high-level values (more than 1) included Australia (1.9692), Canada (1.5734), Germany (1.2516), the United Kingdom (1.2345), South Africa (1.1839), France (1.1365), the United States (1.0532), and Italy (1.0358); the mid-level values (0.5 to 1) included Japan (0.9078), the Republic of Korea (0.8505), Brazil (0.7306), China (0.7157), and Mexico (0.7038); and the low-level values 
(less than 0.5) included Indonesia (0.4572), the Russian Federation (0.4555), Saudi Arabia (0.3596), Argentina (0.3514), India (0.2887), and Turkey (0.1710).

\subsection{Level of Synergy Innovation of National AISs}

In order to identify the level of synergy innovation of the G20 countries' national AISs under the current control variables, the solutions of the order parameter equation were calculated (see Equation (8)] over time (shown in Figure 2). All of the computations were performed with the help of Matlab 2016a.

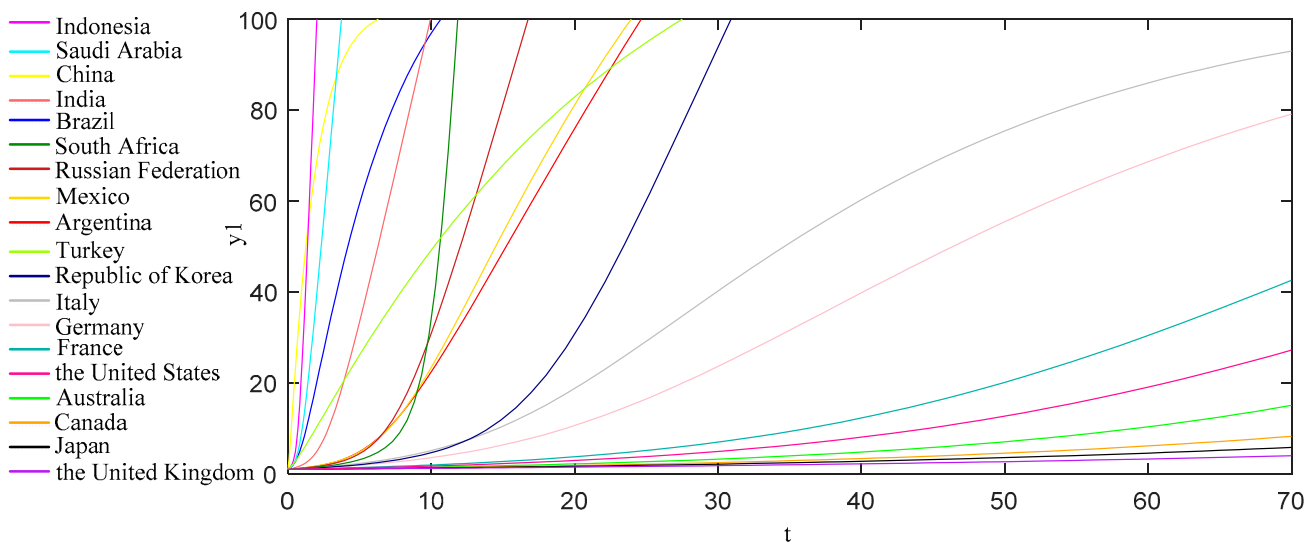

Figure 2. Evolutionary trajectories of the order parameters under the current control variables.

As can be seen in Figure 2, all of the evolutionary trajectories of the order parameters of G20 countries under current control variables increased with time. This indicated that the subsystems matched and synergized with each other, promoting the transformation of the national AIS into a more advanced self-organized synergistic state. Moreover, the trajectory groups were divided into three categories. The first-echelon national AISs were in the active period of synergy, the second-echelon national AISs were in the stable period, and the third-echelon national AISs were in the general period.

\section{(1) Active synergy}

The evolutionary trajectories of the order parameters in the first-echelon national AISs, including Indonesia (Magenta), Saudi Arabia (Turquoise1), China (Yellow), India (IndianRed1), Brazil (Blue), South Africa (ForestGreen), the Russian Federation (Firebrick), Mexico (Gold), Argentina (Red), Turkey (SpringGreen), and the Republic of Korea (NavyBlue) showed a steep rise in a short amount of time because of the fast-lifting values of the order parameters in the $0-40$ period. The results indicated that the countries in the first echelon had national AISs in the active period of synergy, and the top five countries expressed especially stronger synergistic rising powers.

\section{(2) Stable synergy}

The evolutionary trajectories of the order parameters of the second-echelon national AISs steadily increased in the 0-70 period, and the rising trend in Italy (Grey) was more significant than that in Germany (Pink). The second-echelon countries were in the stable period of synergy, in which synergistic rising powers were relatively weak.

\section{(3) General synergy}

A common weakness of the third-echelon national AISs was that there was no significant order parameter in the 0-40 period, and low increasing evolutionary trajectories of the order parameters in the 40-70 period. The results might be attributed to the weaker synergistic rising powers. The third-echelon included France (LightSeaGreen), the United States (DeepPink), Australia (Green), Canada (Orange), Japan (Black), and the United Kingdom (Purple), which were in the general period of synergy. 


\subsection{Change of Order Parameters under Different Control Variables}

The evolutionary trajectories of the order parameters of the G20 countries under different control variables are shown in Figure 3. The red ' ${ }^{*}$, blue ' - ', and orange ' + ' represent the simulation results under the current control variables, which are 0.5 greater than the current value, and one-half of the current value, respectively.

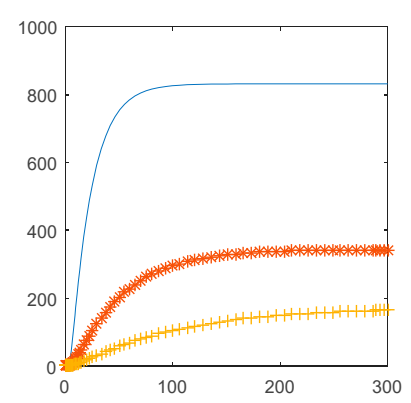

(a) Argentina



(c) Brazil



(e) China



(g) Germany

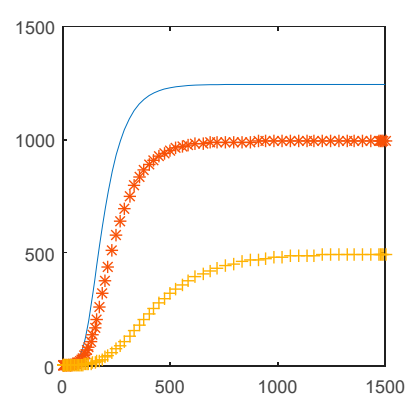

(b) Australia

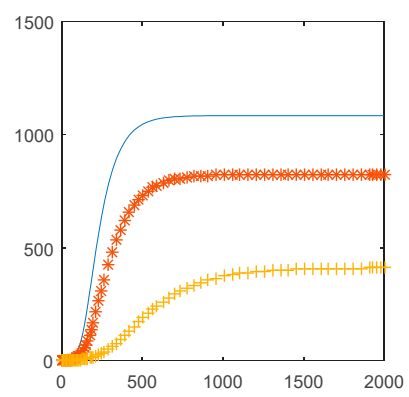

(d) Canada

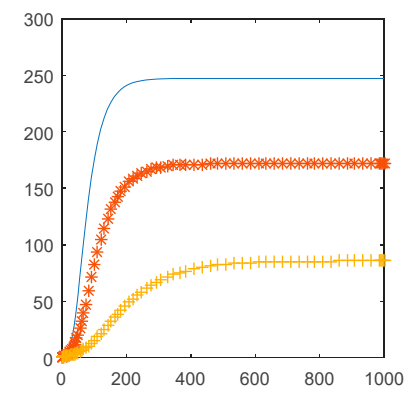

(f) France

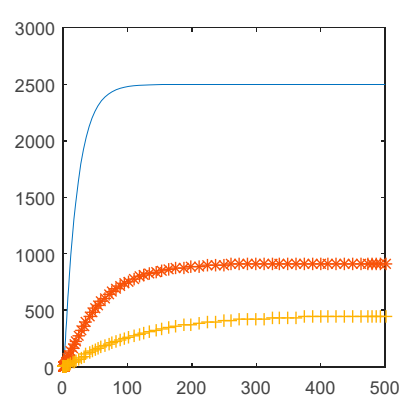

(h) India

Figure 3. Cont. 




(i) Indonesia

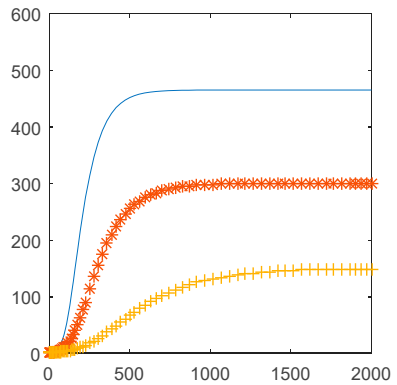

(k) Japan

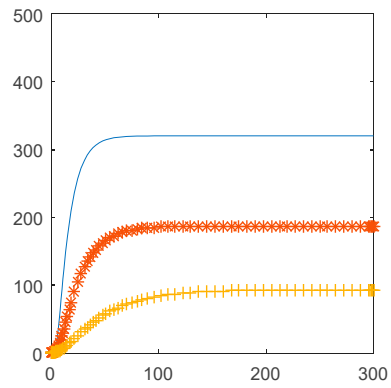

(m) Mexico

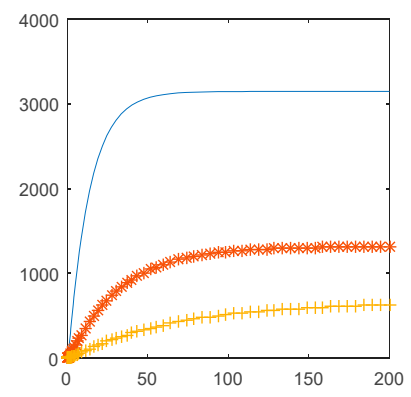

(o) Saudi Arabia

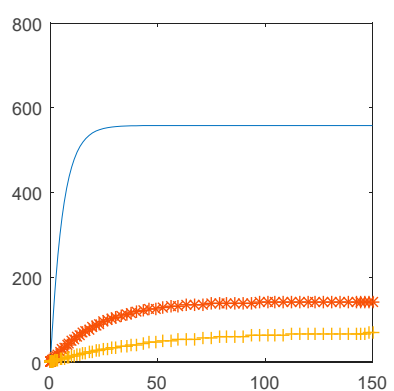

(q) Turkey



(j) Italy

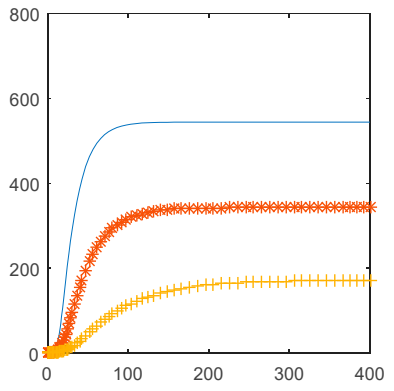

(1) Republic of Korea

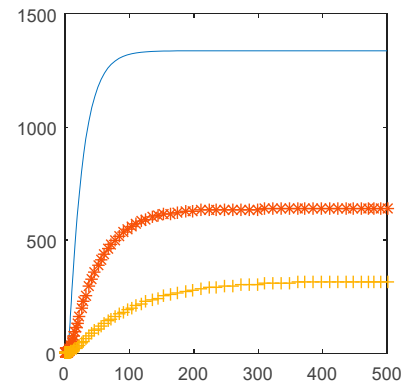

(n) Russian Federation



(p) South Africa

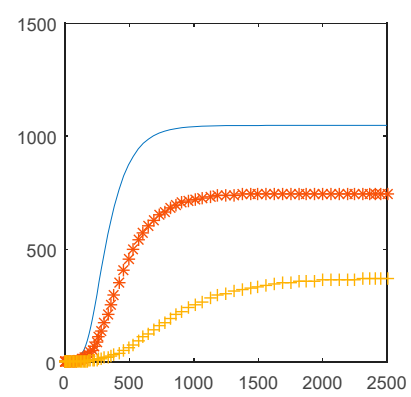

(r) the United Kingdom

Figure 3. Cont. 




(s) the United States

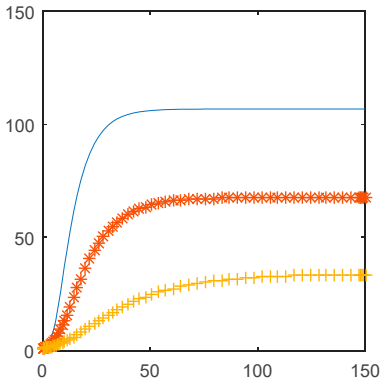

(t) average-value of G20

Figure 3. Change trajectories of the order parameters under different control variables.

As shown in Figure 3, on the one hand, when the values of the control variables were greater than the current values (e.g., 0.5 greater than the current values), the order parameters of national AISs were at higher levels from the beginning. The greater the values of the control variables, the higher the order parameters. Nevertheless, when the values of the control variables were lower than the current values (e.g., one-half of the current values), the order parameters of national AISs were at poor levels from the start. On the other hand, when the extent of the control variable promotion was the same ( 0.5 greater than the current values), the order parameters of some countries (India, Indonesia, Saudi Arabia, and South Africa) (raised above 1000) improved significantly compared with others (Brazil, China, France, Germany, Italy, and the United States) (raised below 100). The results indicated that there were more obstacles for countries without significant improvements to achieving a more advanced self-organized synergistic state.

\section{Discussion}

In this section, we carried out the discussion of research results in relation to the synergy of G20 countries' national AISs, taking into account sustainable agricultural development.

\subsection{Optimization of Innovation Indicators}

The results of parameters inform us that most developed countries were stronger in innovation allocation and innovation output, but weaker in innovation potentiality; on the contrary, most developing countries had comparatively stronger innovation potentialities, but a weaker performance in innovation allocation and innovation output. Better innovation elements are the foundation of active synergy innovation. Most of the developed countries that had a relatively higher innovation allocation and innovation output, but lower innovation potentiality, especially with weaker synergistic rising powers (e.g., France, the United States, Australia, Canada, Japan, and the United Kingdom), should focus on strengthening the indicators with a weak innovation potentiality (as shown in Table 7) while maintaining high standards of innovation allocation and innovation output. Note: ' $\sqrt{ }$ ' marks the three weakest indicators.

In contrast, most of the developing countries with a lower innovation allocation and innovation output, but higher innovation potentiality, should pay more attention to the promotion of the weaker indicators of innovation allocation and output (see Tables 8 and 9). In addition, attracting more foreign resources (such as innovation personnel and money) and relying on excellent potentiality advantages will be a good way to make up for the shortcomings of the developing countries. 
Table 7. Weak potential indicators for the Group of Twenty (G20) developed countries.

\begin{tabular}{|c|c|c|c|c|c|c|c|c|}
\hline $\begin{array}{ll}\text { Indicators } & \text { Countries } \\
\end{array}$ & Australia Canada & France & Germany & Italy & Japan & $\begin{array}{c}\text { The Republic } \\
\text { of Korea }\end{array}$ & $\begin{array}{c}\text { The United } \\
\text { Kingdom }\end{array}$ & $\begin{array}{l}\text { The United } \\
\text { States }\end{array}$ \\
\hline \multicolumn{9}{|l|}{$\begin{array}{l}\text { Growth rate of agricultural } \\
\text { machinery }\end{array}$} \\
\hline \multicolumn{9}{|l|}{$\begin{array}{l}\text { Growth rate of information } \\
\text { and communication } \\
\text { technology }\end{array}$} \\
\hline $\begin{array}{l}\text { Growth rate of } \\
\text { transportation infrastructure }\end{array}$ & $\sqrt{ }$ & $\sqrt{ }$ & & $\sqrt{ }$ & $\sqrt{ }$ & $\sqrt{ }$ & $\sqrt{ }$ & $\sqrt{ }$ \\
\hline \multicolumn{9}{|l|}{$\begin{array}{l}\text { Growth rate of ranking by } \\
\text { agricultural sciences }\end{array}$} \\
\hline $\begin{array}{l}\text { Growth rate of R\&D level of } \\
\text { agricultural enterprises }\end{array}$ & $\sqrt{ }$ & & & & & & & \\
\hline \multicolumn{9}{|l|}{$\begin{array}{l}\text { Growth rate of agricultural } \\
\text { researchers }\end{array}$} \\
\hline $\begin{array}{l}\text { Growth rate of peasant } \\
\text { cultural quality }\end{array}$ & & & & & & $\sqrt{ }$ & & \\
\hline \multicolumn{9}{|l|}{$\begin{array}{l}\text { Growth rate of } \\
\text { university-industry } \\
\text { collaboration }\end{array}$} \\
\hline $\begin{array}{l}\text { Growth rate of cluster } \\
\text { development state }\end{array}$ & $\sqrt{ }$ & & & & & & $\sqrt{ }$ & $\sqrt{ }$ \\
\hline $\begin{array}{l}\text { Growth rate of agricultural } \\
\text { journal papers }\end{array}$ & $\sqrt{ }$ & $\sqrt{ }$ & $\sqrt{ }$ & & & $\sqrt{ }$ & $\sqrt{ }$ & $\sqrt{ }$ \\
\hline $\begin{array}{l}\text { Growth rate of agricultural } \\
\text { patent }\end{array}$ & $\sqrt{ }$ & $\sqrt{ }$ & $\sqrt{ }$ & $\sqrt{ }$ & & & & \\
\hline $\begin{array}{l}\text { Growth rate of plant } \\
\text { varieties }\end{array}$ & & & & & $\sqrt{ }$ & & & \\
\hline \multicolumn{9}{|l|}{$\begin{array}{l}\text { Growth rate of index of } \\
\text { agricultural production }\end{array}$} \\
\hline \multicolumn{9}{|l|}{$\begin{array}{l}\text { Growth rate of agricultural } \\
\text { land productivity }\end{array}$} \\
\hline $\begin{array}{l}\text { Growth rate of agricultural } \\
\text { labor productivity }\end{array}$ & & & $\sqrt{ }$ & $\sqrt{ }$ & $\sqrt{ }$ & & & \\
\hline
\end{tabular}

Table 8. Weak allocation indicators for the G20 developing countries.

\begin{tabular}{|c|c|c|c|c|c|c|c|c|c|c|}
\hline $\begin{array}{ll}\text { Indicators } & \text { Countries }\end{array}$ & Argentina & Brazil & China & India & Indonesia & Mexico & $\begin{array}{l}\text { The Russian } \\
\text { Federation }\end{array}$ & $\begin{array}{l}\text { Saudi } \\
\text { Arabia }\end{array}$ & $\begin{array}{l}\text { South } \\
\text { Africa }\end{array}$ & Turkey \\
\hline $\begin{array}{l}\text { Agricultural } \\
\text { machinery }\end{array}$ & $\sqrt{ }$ & $\sqrt{ }$ & $\sqrt{ }$ & & $\sqrt{ }$ & $\sqrt{ }$ & $\sqrt{ }$ & $\sqrt{ }$ & $\sqrt{ }$ & \\
\hline \multicolumn{11}{|l|}{$\begin{array}{l}\text { Information and } \\
\text { communication } \\
\text { technology }\end{array}$} \\
\hline \multicolumn{11}{|l|}{$\begin{array}{l}\text { Transportation } \\
\text { infrastructure }\end{array}$} \\
\hline $\begin{array}{c}\text { Ranking by } \\
\text { agricultural sciences }\end{array}$ & $\sqrt{ }$ & & & $\sqrt{ }$ & $\sqrt{ }$ & $\sqrt{ }$ & $\sqrt{ }$ & $\sqrt{ }$ & $\sqrt{ }$ & $\sqrt{ }$ \\
\hline $\begin{array}{c}\text { R\&D level of } \\
\text { agricultural enterprises }\end{array}$ & $\sqrt{ }$ & $\sqrt{ }$ & $\sqrt{ }$ & $\sqrt{ }$ & $\sqrt{ }$ & & $\sqrt{ }$ & $\sqrt{ }$ & $\sqrt{ }$ & $\sqrt{ }$ \\
\hline $\begin{array}{l}\text { agricultural } \\
\text { researchers }\end{array}$ & & $\sqrt{ }$ & $\sqrt{ }$ & $\sqrt{ }$ & & $\sqrt{ }$ & & & & $\sqrt{ }$ \\
\hline \multicolumn{11}{|l|}{$\begin{array}{l}\text { Peasant cultural } \\
\text { quality }\end{array}$} \\
\hline \multicolumn{11}{|l|}{$\begin{array}{l}\text { University-industry } \\
\text { collaboration }\end{array}$} \\
\hline $\begin{array}{c}\text { State of cluster } \\
\text { development }\end{array}$ & & & & & & & & & & \\
\hline
\end{tabular}


Table 9. Weak output indicators for the G20 developing countries.

\begin{tabular}{|c|c|c|c|c|c|c|c|c|c|c|}
\hline $\begin{array}{ll}\text { Indicators } & \text { Countries }\end{array}$ & Argentina & Brazil & China & India & Indonesia & Mexico & $\begin{array}{l}\text { The Russian } \\
\text { Federation }\end{array}$ & $\begin{array}{l}\text { Saudi } \\
\text { Arabia }\end{array}$ & $\begin{array}{l}\text { South } \\
\text { Africa }\end{array}$ & Turkey \\
\hline $\begin{array}{l}\text { Agricultural journal } \\
\text { papers }\end{array}$ & & & $\sqrt{ }$ & $\sqrt{ }$ & $\sqrt{ }$ & & $\sqrt{ }$ & & $\sqrt{ }$ & \\
\hline Agricultural patent & $\sqrt{ }$ & $\sqrt{ }$ & $\sqrt{ }$ & $\sqrt{ }$ & $\sqrt{ }$ & $\sqrt{ }$ & $\sqrt{ }$ & $\sqrt{ }$ & $\sqrt{ }$ & $\sqrt{ }$ \\
\hline Plant varieties & & $\sqrt{ }$ & & $\sqrt{ }$ & $\sqrt{ }$ & $\sqrt{ }$ & & $\sqrt{ }$ & & $\sqrt{ }$ \\
\hline \multicolumn{11}{|l|}{$\begin{array}{l}\text { Index of agricultural } \\
\text { production }\end{array}$} \\
\hline \multicolumn{11}{|l|}{$\begin{array}{l}\text { Agricultural land } \\
\text { productivity }\end{array}$} \\
\hline $\begin{array}{l}\text { Agricultural labor } \\
\text { productivity }\end{array}$ & $\sqrt{ }$ & $\sqrt{ }$ & $\sqrt{ }$ & & & $\sqrt{ }$ & $\sqrt{ }$ & & & $\sqrt{ }$ \\
\hline $\begin{array}{l}\text { Agricultural value } \\
\text { added }\end{array}$ & $\sqrt{ }$ & & & & & & & $\sqrt{ }$ & $\sqrt{ }$ & \\
\hline
\end{tabular}

\subsection{Improvement of National AIS}

National AIS is the organization and operation carrier of the national ASTI activities [6]. The complex structures of the national AIS lead to the formation and development of ASTI capability through multiple factors. Therefore, the fundamental way to enhance capability is to break through the bottlenecks that limit synergy by constructing national AISs. Most of the developed countries have formed relatively perfect national AISs, although they were all in the stable period (including Italy and Germany) or the general period of synergy (including France, the United States, Australia, Canada, Japan, and the United Kingdom), in which weaker synergistic rising powers are expressed. Meanwhile, as a dynamic concept, ASTI has different contents and requirements in different periods. Therefore, the national AIS also needs to keep pace with the times to achieve continuous improvement. The developed countries should pay attention to the further optimization of the existing national AIS. All of the developing countries of the G20 are in the active period of synergy. However, most of them have not completely set up a national AIS in line with the social and economic development progresses. In order to achieve sustainable synergetic development, governments should establish or promote the existing structure of the AIS, based on the current situation of their national AIS and extensive references to some mature AIS models [6,9]. The core content of system optimization is to improve the balance and synergy among the various components, systematize the scattered parts, and integrate the divergent functions.

\subsection{Promotion of Government Policy Supports}

The change results of the order parameters under different control variables illustrated that strong government policy supports played a positive role in promoting interaction and collaboration among innovation elements. Three suggestions were proposed based on the indicators of the control variable of government policy (Political stability, Support for ASTI, and Intellectual property protection and policy rationality). First, political instability is regarded by economists as a serious malaise that is harmful to economic performance $[29,30]$. By increasing uncertainty about the future, it may lead to a less efficient resource allocation and lower productivity growth, and reduce human capital accumulation as well as research and development efforts by innovative actors, leading to slower technological progress [30]. Thus, governments should endeavor to build a peaceful and stable international environment for economic development, including agricultural innovation development. Second, policy-makers need to pay more attention to agricultural science, technology, and innovation. They should get rid of the ideological obstacles and institutional barriers in order to improve the management of innovative personnel, increase the innovative investment, and attach importance to intellectual property protection. Third, the rationality of the promotion of the agricultural innovation policy includes: (1) choosing the self-organization development route, which is a highly optimized way of evolving nature and society over a long period of time [31], following the self-organizing rule of national AISs; (2) strengthening the macro coordination of innovation policies and regulations, as well 
as dealing with the central-local government relations, internal relations of science departments, and science-non-science department relations in order to avoid repeated policy deployments; (3) improving the efficiency of the formulation of agricultural innovation policy, promoting the innovation policy implementation, as well as emphasizing policy monitor.

\section{Conclusions}

The existing literature about AISs has made considerable progress [32,33], but has failed to empirically investigate the synergy of national AISs based on the self-organization theory and methodology.

This paper aimed to explore this new direction in AIS research. First, an analytical model for the study of the synergy of national AISs based on the B-Z reaction was developed. A set of logistical regression equations consisting of three state variables (innovation allocation variable, innovation output variable, and innovation potentiality variable), three adjustment parameters, and one control variable was used to simulate the process of the synergy evolution of national AISs. Secondly, our empirical analysis selected a broad set of indicators describing the three state variables and control variable, calculated the values of the three adjustment parameters corresponding to the state variables and the control variable for a panel of G20 countries, and then obtained the evolutionary trajectories of the order parameters under different control variables. The evolutionary trajectories of the order parameters were used to investigate the self-organized synergistic patterns of the G20 countries. Thirdly, some policy suggestions, simultaneously taking into account the optimization of the innovation indicators, improvement of the national AISs, and promotion of government policy supports, were provided.

On the whole, this study contributed to theory-building and policy-making in the following ways. For theory building, the investigation of the synergy of national AISs could complement and inform the research of AISs and offer a better insight into the synergistic attributes of systems. Good synergy among the various innovation elements contributes to the sustainable development of AISs. Moreover, sustainable AISs help to speed up innovation production, diffusion, and translation in a sustainable manner. For policy-making, public policies, based on three aspects (optimization of innovation indicators, improvement of national AISs, and promotion of government policy supports) should help to promote the rational allocation of agricultural innovation resources, optimize the synergistic relationship of the multi-components, and thereby achieve the sustainable development of AISs.

The limitations of our study are certainly interesting and worthy of further exploration. A national AIS is a complex system whose synergy is driven by various factors. Any given change in one of the factors composing an AIS has a series of direct and indirect effects on the synergy innovation process. This study explicitly analyzed and selected a broad set of innovation indicators describing the three state variables and the control variable, although it was still a relatively simple indicator index within which some practical complexities were not taken into account. We will attempt to investigate more detailed indicators for a better simulation of national AISs and develop objectives and specific strategies for government policy supports in the future.

Author Contributions: D.W. and X.G. conceived and designed this study. D.W. processed the data, performed the experiments and wrote the paper. X.D. collected the data. J.S. provided valuable guidance in the different stages of implementation. Y.C. provided the editing service. All the authors contributed to the analysis and interpretation of the results. They all read and approved the final manuscript.

Funding: This research is supported by the Chinese Postdoctoral Science Foundation (2017M621239) and the Postdoctoral Science Foundation of Heilongjiang Province (LBH-Z17007).

Acknowledgments: We are grateful for the helpful insights and suggestions from the editor of this journal, Vanessa $\mathrm{Bu}$, as well as the anonymous referees.

Conflicts of Interest: The authors declare no conflict of interest. 


\section{References}

1. Ortiz, O.; Orrego, R.; Pradel, W.; Gildemacher, P.; Castillo, R.; Otiniano, R.; Gabriel, J.; Vallejo, J.; Torres, O.; Woldegiorgis, G.; et al. Insights into potato innovation systems in Bolivia, Ethiopia, Peru and Uganda. Agric. Syst. 2013, 114, 73-83. [CrossRef]

2. Dutta, S.; Lanvin, B.; Wunsch-Vincent, S. The Global Innovation Index 2017: Innovation Feeding the World; Cornell University: Ithaca, NY, USA; INSEAD: Paris, France; The World Intellectual Property Organization: Geneva, Switzerland, 2017; p. 42.

3. Samara, E.; Georgiadis, P.; Bakouros, I. The impact of innovation policies on the performance of national innovation systems: A system dynamics analysis. Technovation 2012, 32, 624-638. [CrossRef]

4. Meynard, J.M.; Casabianca, F. Agricultural systems and the innovation process. In New Trends for Innovation in the Mediterranean Animal Production; Bouche, R., Derkimba, A., Casabianca, F., Eds.; EAAP Publication No. 129; Wageningen Academic Publishers: Wageningen, The Netherands, 2011; pp. 17-26.

5. Hall, A.; Sulaiman, V.R.; Clark, N.; Yoganand, B. From measuring impact to learning institutional lessons: An innovation systems perspective on improving the management of international agricultural research. Agric. Syst. 2003, 78, 213-241. [CrossRef]

6. Wang, D.; Zhao, X.L.; Guo, X.Y.; Hu, Y.; Du, X. Theoretical framework and capability evaluation for the national agricultural science, technology and innovation-An empirical study based on the group of twenty. China Soft Sci. 2018, 3, 18-35.

7. Hall, A. Challenges to strengthening agricultural innovation systems: Where do we go from here? In Farmer First Revisited: Innovation for Agricultural Research and Development; Scoones, I., Thomson, J., Eds.; Practical Action Publishing: Sussex, UK, 2009; pp. 30-38.

8. Klerkx, L.; Aarts, M.N.C.; Leeuwis, C. Adaptive management in agricultural innovation systems: The interactions between innovation networks and their environment. Agric. Syst. 2010, 103, 390-400. [CrossRef]

9. Spielman, D.J.; Ekboir, J.; Davis, K.; Ochieng, C.M.O. An innovation systems perspective on strengthening agricultural education and training in sub-Saharan Africa. Agric. Syst. 2008, 98, 1-9. [CrossRef]

10. Lamprinopoulou, C.; Renwick, A.; Klerkx, L.; Hermans, F.; Roep, D. Application of an integrated systemic framework for analysing agricultural innovation systems and informing innovation policies: Comparing the Dutch and Scottish agrifood sectors. Agric. Syst. 2014, 129, 40-54. [CrossRef]

11. Klerkx, L.; Schut, M.; Leeuwis, C.; Kilelu, C. Advances in knowledge brokering in the agricultural sector: Towards innovation system facilitation. IDS Bull. 2012, 43, 53-60. [CrossRef]

12. Clark, N. Innovation systems, institutional change and the new knowledge market: Implications for third world agricultural development. Econ. Innov. New Technol. 2002, 11, 353-368. [CrossRef]

13. Schut, M.; Rodenburg, J.; Klerkx, L.; Kayeke, J.; Van Ast, A.; Bastiaans, L. RAAIS: Rapid appraisal of agricultural innovation systems (Part II). Integrated analysis of parasitic weed problems in rice in Tanzania. Agric. Syst. 2015, 132, 12-24. [CrossRef]

14. Hall, A. Capacity development for agricultural biotechnology in developing countries: An innovation systems view of what it is and how to develop it. J. Int. Dev. 2005, 17, 611-630. [CrossRef]

15. Spielman, D.J.; Birner, R. How Innovative is Your Agriculture? Using Innovation Indicators and Benchmarks to Strengthen National Agricultural Innovation Systems; World Bank: Washington, DC, USA, 2008.

16. Li, R.; Ju, X.F.; Liu, M.Z. The evolution mechanism and models analysis of technological innovation system based on self-organization theory. Oper. Res. Manag. Sci. 2010, 19, 145-151.

17. Lu, D.N.; Zhang, N. Study on the self-organizing evolution mechanism of agricultural technological innovation system. Agric. Econ. 2011, 9, 20-21.

18. Haken, H. Self-organization. Scholarpedia 2008, 3, 1401. [CrossRef]

19. Kline, S.J.; Rosenberg, N. An overview of innovation. In Studies on Science and the Innovation Process; Rosenberg, N., Ed.; World Scientific: Singapore, 2009; pp. 173-203.

20. Haken, H. Cooperative phenomena in systems far from thermal equilibrium and in nonphysical systems. Rev. Mod. Phys. 1975, 47, 67. [CrossRef]

21. Schiepek, G.; Perlitz, V. Self-organization in clinical psychology. Encyclopedia of Complexity and Systems Science; Springer: New York, NY, USA, 2009; pp. 7991-8009.

22. Field, R.J.; Koros, E.; Noyes, R.M. Oscillations in chemical systems. II. Thorough analysis of temporal oscillation in the bromate-cerium-malonic acid system. J. Am. Chem. Soc. 1972, 94, 8649-8664. [CrossRef] 
23. Field, R.J.; Noyes, R.M. Oscillations in chemical systems. IV. Limit cycle behavior in a model of a real chemical reaction. J. Chem. Phys. 1974, 60, 1877-1884. [CrossRef]

24. Su, Y.; Jiang, X.S.; Lei, J.S.; Lin, Z.Z. Research on collaborative evolution of regional innovation system. China Soft Sci. 2016, 3, 44-61.

25. Zhang, T.N.; Han, B.; Zhang, Y.J. Enterprise system co-evolution model based on "B-Z" reaction. J. Manag. Sci. China 2011, 2, 42-52.

26. Dong, H.M.; Li, B.Z. A study for collaborative innovation active of the research institutes based on knowledge triangle. Sci. Res. Manag. 2017, 5, 107-114.

27. Wang, D.; Zhao, X.L.; Zhang, Z.Z. The time lags effects of innovation input on output in national innovation systems: The case of China. Discret. Dyn. Nat. Soc. 2016, 8, 1-12. [CrossRef]

28. Hayami, Y.; Kikuchi, M.; Morooka, K. Market price response of world rice research. Agric. Econ. 1989, 3, 333-343. [CrossRef]

29. Alesina, A.; Perotti, R. Income distribution, political instability, and investment. Eur. Econ. Rev. 1996, 40, 1203-1228. [CrossRef]

30. Aisen, A.; Veiga, F.J. How does political instability affect economic growth? Eur. J. Polit. Econ. 2013, 29, 151-167. [CrossRef]

31. Tong, W. Outline for self-organizing methodology. J. Syst. Dialect. 2001, 9, 4-10.

32. Hermans, F.; Stuiver, M.; Beers, P.J.; Kok, K. The distribution of roles and functions for upscaling and outscaling innovations in agricultural innovation systems. Agric. Syst. 2013, 115, 117-128. [CrossRef]

33. Douthwaite, B.; Hoffecker, E. Towards a complexity-aware theory of change for participatory research programs working within agricultural innovation systems. Agric. Syst. 2017, 155, 88-102. [CrossRef]

(C) 2018 by the authors. Licensee MDPI, Basel, Switzerland. This article is an open access article distributed under the terms and conditions of the Creative Commons Attribution (CC BY) license (http:/ / creativecommons.org/licenses/by/4.0/). 